\title{
Myelomatous Meningitis- a case report and review of literature
}

\author{
${ }^{1}$ Hegde V. K, ${ }^{2}$ Bajpai. M \\ ${ }^{1}$ Assistant prof pathology, pariyaram medical college, Kannur, Kerala \\ ${ }^{2}$ Assistant prof pathology, hind institute of medical sciences, safedabad,Barabanki U.P
}

\begin{abstract}
Multiple Myeloma (MM) is a neoplastic disease of plasma cells characterized by the production of monoclonal immunoglobulin. Myelomatous meningitis is a rare occurrence in multiple myeloma. The signs and symptoms of meningeal myelomatosis are non-specific. The diagnosis of meningeal myelomatosis depends on the demonstration of malignant plasma cells in the cerebrospinal fluid. A combination of radiation therapy and chemotherapy is the usual treatment. We report the case of a woman with myelomatous meningitis. Multiple myeloma was diagnosed by serum protein electrophoresis and bone marrow aspiration.This case and a review of the literature show that clinical manifestations of meningeal myeloma are non-specific .
\end{abstract}

Keywords: Multiple Myeloma,Myelomatous Meningitis,Bone marrow

\section{Introduction}

Multiple Myeloma (Mm) is a Neoplastic disease of Plasma Cells with a few cases of Central Nervous System (CNS) involvement reported. Signs and Symptoms of CNS involvement are non-specific. The diagnosis of Meningeal Myelomatosis depends on the demonstration of Malignant Plasma Cells in the CSF. ${ }^{1}$ We report a case of Myelomatous Meningitis.

Materials and Methods: The present case was studied at Kasturba Medical College, Mangalore, Karnataka. A lumbar puncture was performed and the cerebrospinal fluid was subjected to biochemical and cytological analysis. Pap stained smears were examined. Serum electrophoresis, and a non-contrast computed tomography (CT) scan were also done.

\section{Results}

The serum electrophoresis showed a prominent M-band. Non-contrast CT scan was normal. The CSF biochemistry revealed an increased protein $(92.6 \mathrm{mg} \%)$, a low glucose $(56 \mathrm{mg} \%)$ and a high white cell count $\left(24 \mathrm{cells} / \mathrm{mm}^{3}\right)$. The CSF cytology showed cells with eccentric nucleus and paranuclear halo suggestive of plasma cells. Few showed prominent nucleoli suggestive of plasmablasts. Thus, a dignosis of meningeal myelomatosis was confirmed. However, the patient refused further investigations and treatment. The patient expired one year after the diagnosis was confirmed.

\section{Discussion}

Plasma cells are not a component of normal CSF. ${ }^{2}$ Approximately $1 \%$ of MM patients develop CNS myeloma. ${ }^{3}$ Myelomatous meningitis may originate in the plasma cells that spread to the meninges through thin walled microscopic veins in the arachnoid membrane ${ }^{3,4}$ or MM may disseminate via circulating lymphocytes that may be progenitors of myeloma cells. ${ }^{5}$

Meningeal involvement in MM may arise in the absence of circulating plasma cells ${ }^{6}$. Signs and symptoms of myelomatous meningitis are non specific and include altered mental status, muscle weakness,encephalopathic syndrome,cranial nerve palsy, spinal root involvement. Sensory disturbances are rare. Accurate diagnosis of myelomatous meningitis is made on CSF examination by demonstration of plasma cells ${ }^{7}$, monoclonal spikes on electrophoresis ${ }^{7}$ and monoclonal immunoglobulin in the cytoplasm of plasma cells. ${ }^{8}$ The treatment of meningeal myeloma has not been established. Intrathecal administration of methotrexate,cytarabine and craniospinal irradiation has been given in most cases. ${ }^{6}$ The ultimate prognosis is however, poor.

The other conditions which show plasma cells in CSF are Subacute Sclerosing PanEncephalitis ${ }^{9}$, Neurocysticercosis ${ }^{10}$, Mollaret's meningitis ${ }^{11}$, Tuberculous meningitis ${ }^{12}$

\section{Conclusion}

The clinical features of leptomeningeal myeloma are non specific. Therefore cytological and immunocytochemical examination of CSF in patients with MM must be done to diagnose myelomatous meningitis in such patients 


\section{References}

[1] Bruyn GAW, Zwetsloot CP, Niewkoop JAV, Ottolander GJD, Padberg GW. Cranial nerve palsy as a presenting feature of

[2] secondary plasma cell leukaemia. Cancer 1987,60(4):906-909.

[3] Henry;s clinical diagnosis and management by laboratory methods. $21^{\text {st }}$ edn,chap. $28 . p g 429$.

[4] Chang H, Barlett ES, Patterson B, Chen CI,Yi QL. The absence of CD56 on malignant plasma cells in the CSF is the hallmark of MM involving the CSF. British J Hematol;129:539-541.

[5] Price RA,Johnson WW. The CNS in childhood leukaemia:the arachnoid. Cancer 1973;31:520-533.

[6] Spier ASD, Halpern R, Ross SC et al. Meningeal myelomatosis. Arch Intern Med 1980;140:256-259.

[7] Cavanna L, Invernizzi R, Berte R, Vallisa D, Buscarini L. Meningeal involvement in multiple myeloma. Acta cytol 1996;40(3):571575

[8] Oda k et al. Meningeal involvement in Bence-Jones multiple myeloma. Cancer 1991;67:1900-1902.

[9] Sasser RL, Yam LT, Cy L. Myeloma with involvement of serous cavities. Acta Cytol 1990;34:479-485.

[10] Comert S et al. SSPE presenting as acute disseminated encephalomyelitis. Ind J Paed 2006;73:1119-1121

[11] Nikolik;leptomeningeal form of neurocysticercosis with chronic meningitis. European congress of clinical microbiology and infectious disease. May 1-4,2004

[12] Theresa YC et al. Mollarets meningitis: cytopathologic analysis of 14 cases. Diag cytopath;28:5:227-31.

[13] R D;souza et al. Atypical presentation of TB meningitis:a case report.SMJ 2002: 47(1)14-15.

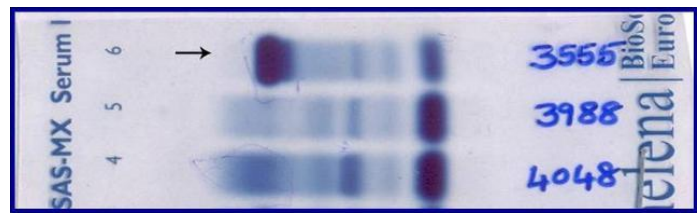

Figure 1: Serum electrophoresis showing $M$ band (arrow)

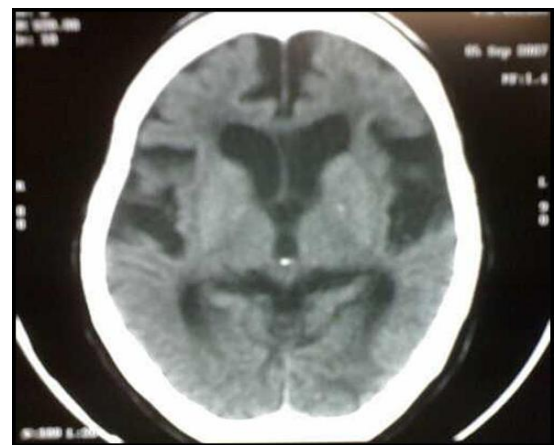

Figure 2: plain CT brain is unremarkable

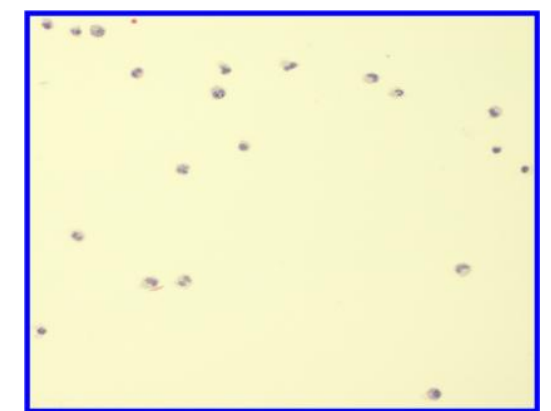

Figure 3: CSF pleocytosis (pap X 100)

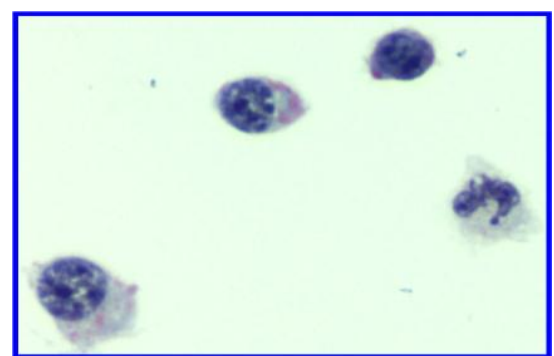

Figure 4: plasma cells in the CSF (pap $X$ 400) 